\title{
Education in the Covid-19 Era
}

\section{"We will find a way or we will make it": Facing the Challenges of the Pandemic in Education}

A huge number of scientific journals in the world are rightly dedicated to the impact of the Covid-19 pandemic on education. Regardless of the level of development of the country and the level of digitalisation in education, all countries found themselves in a situation for which they were not prepared. Of course, the situation was much more difficult in those countries that did not have well-developed basic preconditions for dealing with full online teaching (infrastructure, internet connection, digitally literate teachers and students, good cooperation with parents, etc.). The response of education to such circumstances is extremely important, both because of the number of students and teachers who have faced the challenge and due to the generality of the phenomenon and the strength of the impact. There have been huge changes in education: in the organisation of schooling at all educational levels, in communication between teachers and students, and in the realisation of the teaching and learning process.

This special issue of the CEPS Journal aims to make room for new experiences and insights, to define challenges and exchange experiences, and to analyse the factors that have influenced education and the ways - coping strategies - for dealing with "educational stress" in the given circumstances. The aim of the special issue is to analyse the experiences of different countries, different socio-cultural contexts and different subjects, as well as the different perceptions of teachers, students, parents and institutions, in order to gain insights into and better understand the process of education in crisis circumstances. However, we are well aware that after the pandemic subsides, nothing will be exactly the same as in pre-pandemic education.

Defining a problem is half the solution, so asking the right questions is just as important as giving answers. That is why we are very happy that this special issue raises both general questions about the educational crisis and questions about the future of education, what it will look like in the post-Covid era. Such questions are crucial because they force us to look at things from a meta-position and to try to cope with change, not just suffer its consequences. The first block of texts is of this nature: they help to provide the "big picture". This block contains five texts that we can characterise as complementary. Each of them looks at the impact of the Covid-19 pandemic on education, but from different angles and from different levels. 


\section{Block One:}

\section{Where are we in the vortex of pandemic challenges in education?}

The block opens with a text by Professor Emeritus Lorin W. Anderson: Schooling Interrupted: Educating Children and Youth in the Covid-19 Era. By the start of the 2020, pandemic research studies on the use and effectiveness of distance education had focused almost exclusively on higher education, with a negligibly small number of studies related to primary education, such as K12 education. This paper provides an overview of the findings of the latest "emergency remote teaching" (ERT) research in K-12 education and how it has affected students. Unfortunately, there is a lot of evidence all over the world that school closures have had negative effects on student learning. New terms have emerged, such as "Covid slide" or "learning loss", which clearly indicate a significant reduction in existing knowledge and a large loss in school effectiveness (according to a World Bank analysis, this represents from three to nine months of loss per school year). In addition, there is evidence of an increase in disengagement (student attendance has decreased, with roughly twice the level as before school closures), mental health problems and other indicators that students are endangered by the crisis. All of the effects of the pandemic are much greater among socio-culturally vulnerable groups of children and youth (poor, racial and ethnic minority students, children with disabilities, children in rural areas and foster care, homeless children and migrants).

The article The Covid-19 Learning Crisis as a Challenge and an Opportunity for Schools: An Evidence Review and Conceptual Synthesis of Research-Based Tools for Sustainable Change, by Riikka Hofmann, Gabrielle Arenge, Siobhan Dickens, Javiera Marfan, Mairead Ryan, Ngee Derk Tiong, Bhaveet Radia and Lenka Janik Blaskova, logically continues the consideration begun in the previous paper. The authors applied cultural-historical activity theory to reinterpret evidence on widespread learning loss and increasing educational inequities resulting from the pandemic. In fact, they reframe the risk into possibility, identifying scalable transformative learning opportunities. Schools are seen as transformative agencies, change agents capable of transforming local practice to address the global challenges arising from the pandemic. The authors develop "a problem space map" to enable educators to address local challenges. This map is then integrated with research on tool-mediated professional change in order to identify conceptual tools to capture learning gaps and implement pedagogic interventions at scale, thus enhancing schools' agency in addressing the crisis. On this basis, alternative futures for equitable learning in school are generated. The authors discuss the Covid-19 educational crisis as a unique 
stimulus for professional learning and outline the potential for durable shifts in educational thinking and practice beyond the pandemic.

The next article, Keith S. Taber's The Challenge to Educational Reforms during a Global Emergency: The Case of Progressive Science Education, delves deeper into the nature of these negative effects of the pandemic on education. Based on the example of teaching natural sciences, the author points out a very important finding: in this crisis, progressive elements in teaching are more endangered than traditional elements. The implications of this finding are serious. There is a double challenge: firstly, how to incorporate innovation into education, and secondly, how to make innovation a common practice, a core element of good teaching, not a "luxury" in teaching. How teachers see these progressive elements is extremely important. In the present text, the elements are those related to pedagogy (responding to learners 'alternative conceptions) and those related to the curriculum (teaching about the nature of science). In the ERT situation, new, progressive elements are often seen by teachers as 'extras' rather than 'core' features of practice, as more complex and demanding objectives that are not a priority in crisis management. If innovations are not a natural part of regular teaching practice, if they are not embedded in the essence of the teaching/learning process, they will not survive during a period of emergency. The direct consequence of this is a reduction in the quality of teaching in ERT. If we transfer this finding to the context of less developed countries, then the risk of declining quality of teaching/learning is even greater, because it combines various unfavourable factors (lack of infrastructure for quality online teaching for all students, not enough digitally competent teachers and students to work in the online environment, teaching content and methods of work that are not adapted to new conditions, etc).

All of the issues raised in the previous articles must also be viewed more broadly, e.g., in the light of EU education policy, as the next article has done. The EU's Education Policy Response to the Covid-19 Pandemic: A Discourse and Content Analysis, by Vasileios Symeonidis, Denis Francesconi and Evi Agostini, is a critical conceptual analysis of the EU's systemic reaction to a socioeconomic and environmental crisis that carries a number of dilemmas for education systems. Selected European Union policy papers focused on employment and economic priorities are subjected to an analysis of the narratives used in them (e.g., "education recovery"), focusing on the theoretical and ethical implications and the intended outcomes of the narratives. The serious question of "Educating for (whose) success" (McGregor, 2009) is raised, i.e., problems of schooling in an age of neoliberalism. The main aim of the analysis is to look ahead to a renewal of the European ethical framework towards a responsible 
(ethics of responsibility) and sustainable developmental model. The authors emphasise the importance of a lot of "balancing acts" between neoliberal and very much interventionist approaches, and several compensatory and corrective social measures taken by the EU. According to the authors, in spite of the fact that all of the analysed texts share the common objective that recovery should ensure social fairness and inclusiveness, investing in people is still predominantly conceptualised as a growth and competitiveness factor, and only secondarily as a key instrument for social inclusion. A dramatic crisis like the Covid-19 pandemic should lead to dramatic and radical changes, including organisational change, fundamental human and ecological values, and a strong axiological framework. With these changes, the European education area could become an important agent in creating a new "Social Europe".

Education policy measures to provide education during the Covid-19 pandemic were, as a rule, influenced by political and economic ideology, which directly influences the decisions made. Spain is a real example of this, as shown in the text Educational Policies During the Lockdown: Measures in Spain after Covid-19 by E Enrique-Javier Díez-Gutiérrez and Katherine Gajardo Espinoza. The Autonomous Communities of Spain differ in their approach to education in the Covid-19 pandemic. An analysis of their reference educational crisis documents shows that they are influenced by their dominant politics. There are significant differences between conservative and progressive regions, with the latter being more inclined to implement the recommendations of relevant international organisations (e.g., UNESCO, UNICEF, UN, World Bank). This case provides another example of the fact that education is shaped by a specific sociocultural and economic context.

\section{Second block: \\ The views of teachers, students and parents on the pandemic educational experience}

The second block contains texts that present findings on the educational experiences of teachers, students and parents in the new Covid-19 circumstances. Teachers at all levels had the most difficult task due to the sudden radical changes caused by the closure of schools and the transition to ERT. They were all caught unprepared, but they had to adjust quickly despite all of the difficulties they faced in this endeavour. Before the pandemic, the use of IC technology in teaching was much more prevalent in higher education than in primary or secondary education. When we look at the research findings, however, it is clear that all teachers faced the same problems: they all needed help in moving 
to distance education and reorganising their teaching into a new framework.

This block contains papers on the perception of ERT by teachers, students and/or parents: Faik Özgür Karataş, Sevil Akaygun, Suat Çelik, Mehmet Kokoç and Sevgi Nur Yılmaz, Challenge Accepted: Experiences of Turkish Faculty Members at the Time of Emergency Remote Teaching; Tiina Korhonen, Leenu Juurola, Laura Salo and Johanna Airaksinen, Digitisation or Digitalisation: Diverse Practices of the Distance Education Period in Finland; Tijana Jokić Zorkić, Katarina Mićić and Tünde Kovács Cerović, Lost Trust? The Experiences of Teachers and Students during Schooling Disrupted by the Covid-19 Pandemic; Toni Mäkipää, Kaisa Hahl and Milla Luodonpää-Manni, Teachers' Perceptions of Assessment and Feedback Practices in Finland's Foreign Language Classes During the Covid-19 Pandemic; Mojca Juriševič, Lana Lavrih, Amela Lišić, Neža Podlogar and Urška Žerak, Higher Education Students' Experience of Emergency Remote Teaching during the Covid-19 Pandemic in Relation to Self-Regulation and Positivity; and Melita Puklek Levpušček and Luka Uršič, Slovenian Parents' Views on Emergency Remote Schooling during the First Wave of the Covid-19 Pandemic. Among others, the papers provide the following findings:

- Higher educational institutions responded quickly to the new demands, with many of them rapidly adopting an online system, more rapidly than primary and secondary schools. Although the use of ICT in higher education teaching was more frequent, a huge number of teachers had never taken any form of training regarding online distance education before Covid-19 and encountered remote teaching for the first time.

- The need for new competencies became very clear. Teachers who have received the necessary training for distance teaching as part of their work feel more empowered to teach this way than teachers who have not had such training. For the implementation of digital technology in teaching/ learning, there is a need for competencies for the use of digital technology (digital literacy), the ability of teachers to act as adaptive innovators, and the "digipedagogical competence of the teachers". The latter (see Korhonen et al.), that is, how to use digital technology to benefit the quality of teaching/learning, becomes a critical success factor in the educational field. We see that with new experience, new terminology is developed (learning loss, digital slide, emergency remote teaching, etc.). In this sense, the difference between the terms digitisation and digitalisation in education (Korhonen et al.) is particularly interesting. This distinction indicates the essence of the problem in teaching in an online environment: What are the teaching/learning problems that can be solved with these tools? Tools are evolving much faster than understanding 
the learning process in a new medium, so the distinction between digitisation and digitalisation has gained in importance.

- $\quad$ Reducing the quality of socio-emotional aspects of teaching/learning: less interaction of teachers and students; students were disinterested in classes; teachers had trouble following students' development; teaching was more task-oriented than normal classroom interaction, making it difficult to maintain students' peer interaction; the changes in structural and institutional conditions affected both students' and teachers' expectations of each other, and the incongruence of these expectations fed into feelings of helplessness for both students and teachers, disengagement from learning for students, and the need for repairing and building trust in student-teacher relationships.

- $\quad$ Evaluation of teaching effects:

- Poor teacher performance: many teachers were suspicious about the quality of their remote teaching, with most of them believing that it was not as fruitful as face-to-face teaching.

- Teachers spent more time for remote teaching than face-to-face teaching; the heavy workload made them mentally and physically more tired than teaching in the classroom (see Petek in the last block).

- Teaching was more teacher-centred than in the normal classroom.

- Although remote education was considered very challenging at first, teachers managed to create good practices to be utilised after the era of the Covid-19 pandemic.

- Online teaching, if carefully designed and individualised, can stimulate additional commitment and interest of students in the subject (see Stibi et al. in the third block).

- Most teachers believe that students will gain less knowledge or far less knowledge from distance education than they would from education in the classroom. Most parents agree that such schooling provides students with less knowledge, which is also less consolidated (see Puklek Levpušček and Uršič).

- More attention should be paid to the enhancement of assessment and feedback practices in distance education. Some teachers (in Finland, see Mäkipää, Hahl and Luodonpää-Manni) perceived that assessment and feedback practices were implemented successfully, and that final assessment was realistic and reliable, while many other studies indicate less relevancy of grades obtained online, increased cheating in grading due to the digital environment making cheating easier, and usual assessment formats becoming unfeasible (see 
Anderson in the first block, and Matić in the last). Online teaching facilities allow teachers to provide students with more individual feedback.

- Parents of primary school adolescents reported having the most difficulty coordinating work commitments and the remote schooling of their child, and rated emergency remote schooling as more complicated and difficult than traditional classroom instruction.

- Parents also reported more difficulty motivating their child to complete schoolwork at home.

- Parents of high school graduates were most likely to miss personal contact with the teacher and rated emergency remote schooling as more stressful than usual. Parents perceived teachers' remote help to students quite positively.

\section{Third block:}

\section{The response of different subjects to the challenges of the pandemic}

The third block contains articles focused on teaching various school subjects with the realisation of ERT. As we saw in the previous block, the quality of teaching/learning in ERT was influenced by many factors. One of them is the nature of the subject, that is, the nature of the scientific or artistic discipline to which the subject belongs. Three studies refer to teaching physical education, craft pedagogy and physics education, respectively, that is, to teaching subjects that unavoidably involve practical work, often group work. These articles - Tanja Petrušič and Vesna Štemberger, Effective Physical Education Distance Learning Models during the Covid-19 Epidemic; Anna Kouhia, Kaiju Kangas and Sirpa Kokko, The Effects of Remote Pandemic Education on Crafts Pedagogy: Opportunities, Challenges, and Interaction; and Ivana Štibi, Mojca Čepič and Jerneja Pavlin, Physics Teaching in Croatian Elementary and High Schools during the Covid-19 Pandemic - describe teachers' management of physical education, craft pedagogy and physics education, respectively, which was supposed to convey learning content related to practical joint activities during distance learning. With regard to physical education teachers, the most effective model was the flipped learning teaching model, whereby students were given an overview in advance of the different forms of teacher video recordings. The least effective was independent work carried out by the students according to instructions prepared by the teacher. In the study of craft pedagogy, remote teaching challenges were related to the unequal distribution of craft materials as well as technical and social resources at different levels of education and in various 
contexts. This study finds that remote teaching is more teacher-centred and task-oriented than normal classroom interaction. In addition to positive aspects hidden in new experiences and work perspectives, the sudden transition from conventional face-to-face teaching to the remote format had a negative impact on physics teaching in elementary and high schools according to the authors of this study, particularly with regard to students' experimental work, which is an essential part of the subject of physics. The findings show the flexibility and responsiveness of physics teachers, an increase in the teachers' workload, a lack of experimental work, and a lack of teacher knowledge (of ICT) and skills as well as equipment for conducting distance teaching. However, it also emerged that online teaching, if carefully designed and individualised, can motivate students in the subject.

Examples of responses of mathematics and mother tongue teachers to the unexpected challenges are presented in the papers: Ljerka Jukić Matić, Croatian Mathematics Teachers and Remote Education During Covid-19: What did They Learn?; and Tomaž Petek, The Opinion of Slovene (Mother Tongue) Teachers on Distance Learning in Primary Schools. The results showed that teachers were available to their students, tried not to burden them with (school) work, and provided daily feedback on their work. In addition, teachers complained about academic dishonesty in distance education. Slovenian language teachers at the primary school level generally had a good attitude towards distance learning, emphasising the greater use of e-materials and the opportunity for formative assessment of students. In their opinion, among the biggest problems of distance learning (Slovenian language) are: teaching is far more tedious than classroom teaching, lack of student participation, lack of non-verbal communication resulting in difficulties in understanding, and some technical issues. Most teachers believe that students will gain less or far less knowledge from distance education than they would gain from classroom education.

\section{Instead of a conclusion:}

\section{Opening new questions}

The Covid-19 pandemic has raised serious issues in education and reopened many basic assumptions for consideration. There were very high expectations that learning in an online environment would bring a revolution in education in the twenty-first century, but this revolution has not eventuated (Salomon \& Perkins, 1996). To date, there are no definitive research answers on the effects of learning in an online environment, and many new questions related to this have been opened during the pandemic. Our joint efforts should 
contribute to improving the understanding of new educational media, revealing their advantages and limitations, and determining how to make the best use of ICT in education. As Hannibal is reported to have said: "We will find a way or we will make it", there is no third option.

\section{Ana Pešikan, Hannele Niemi and Iztok Devetak}

\section{References}

McGregor, G. (2009). Educating for (whose) success? Schooling in an age of neo-liberalism. British Journal of Sociology of Education, 30(3), 345-358.

Salomon, G., \& Perkins, D. (1996). Learning in Wonderland: What computers really offer education? In S. Kerr (Ed.), Technology and the future of education (pp. 111-130). NSSE Yearbook, University of Chicago. 